DOI: 10.12731/2070-7568-2020-4-370-382

УДК 004.91:63.631.5

\title{
РАЗРАБОТКА ТЕМПОРАЛЬНОЙ МОДЕЛИ ДАННЫХ ДЛЯ ПОДБОРА СЕЛЬСКОХОЗЯЙСТВЕННОЙ ТЕХНИКИ \\ С УЧЕТОМ ТЕХНОЛОГИЧЕСКИХ СВОЙСТВ ЗЕМЕЛЬНЫХ УЧАСТКОВ
}

\section{Павлова А.И.}

Оптимальный подбор сельскохозяйственной техники зависит от многих факторов. В числе основных выделяют тяглово-сиепные свойства тракторов и технологические свойства земельных участков. Разработана темпоральная модель данньх, и программа для оптимального выбора сельскохозяйственной техники на языке высокого уровня Pуthon. В программе реализованы авторизация пользователя, работа пользователя с базой данных сельскохозяйственной техники. При этом использована база данных SQLite, позволяющая хранить и обрабатывать данные с применением облачных не клиент-серверных технологий.

Цель: разработка темпоральной модели данных для оптимального подбора сельскохозяйственных машин путем интеграции с пространственной базой данных.

Методы работы: методы проектирования баз данных, методы разработки динамических геоинформационных моделей, методы разработки темпоральных баз данных.

Результаты: разработана темпоральная модель данных, интегрированная с базой геоданных и с базой данных сельскохозяйственной техники. Информация о земельных участках структурирована в пространственной базе геоданных ArcGIS 10 и включает сведения о площади, типе использования, технологических свойствах земельных участков, влияющих на тяглово-сцепные свойства тракторов. Темпоральная модель данных имеет атрибуты времени, необходимые для составления ежедневного плана работ, расчета экономических показателей по механизированной обработке почвы. 
Область применения результатов: предложен методический подход создания темпоральной базы данных необходим для динамической геоинформационной модели, необходимой для принятия решений по оптимальному выбору техники, выбору технологических операџий, решению логистических и других практических задач.

Ключевые слова: база данных; сельскохозяйственная техника; технологические свойства земельных участков; технологические свойства земельных участков.

\section{DEVELOPMENT OF TEMPORAL DATA MODEL FOR SELECTION OF AGRICULTURAL MACHINERY TAKING INTO ACCOUNT TECHNOLOGICAL PROPERTIES OF LAND PLOTS}

\section{Pavlova A.I.}

Optimal selection of agricultural machinery depends on many factors. Among the main ones are traction and coupling properties of tractors and technological properties of land plots. A temporal data model has been developed, and a program for optimal selection of agricultural machinery in the high-level language Python. The program implements user authorization, user's work with a database of agricultural machinery. At the same time, you use the SOUNDite database, which allows you to store and process data using cloud-based non-client-server technologies.

Goal: to develop a temporal data model for optimal selection of agricultural machines through integration with a spatial database.

Methods: database design methods, dynamic geoinformation modelling methods, temporal database development methods.

Results: A temporal data model has been developed, integrated with the geodata database and with the agricultural machinery database. Information on land plots is structured in the spatial database of geodata ArcGIS 10 and includes information on the area, type of use, technological properties of land plots that affect the traction and coupling properties of tractors. The temporal data model has the time attributes 
necessary to draw up a daily work plan, calculate economic indicators for mechanized tillage.

Field of application of results: methodological approach of creation of temporal database is necessary for dynamic geographic information model, which is necessary for making decisions on optimal selection of equipment, selection of technological operations, solution of logistical and other practical problems.

Keywords: database; agricultural equipment; technological properties of land plots; technological properties of land plots.

В настоящее время актуальны исследования по снижению энергетических затрат при обработке почвы и уменьшению колебаний сопротивления почвообрабатывающих орудий сельскохозяйственных машин. В литературе обсуждаются различные варианты снижения тяглового сопротивления сельскохозяйственных машин. Применением конструкции с псевдогидравлической навеской трактора упругого элемента позволяет оптимизировать конструктивные особенности и рассчитать горизонтальную поверхность при разных значениях тяглового сопротивления [1-2]. Использование такого варианта в сцепном устройстве машины направлено на уменьшение динамического воздействия и среднего тяглового усилия при увеличении силы сопротивления. Однако не способствует существенному уменьшению энергозатрат и повышению коэффициента полезного действия агрегата [3-4]. Другой способ снижения тяглового сопротивления сельскохозяйственных машин связан с использованием специальных устройств в виде упругих элементов (пружин) с креплением стоек рабочих органов к раме машины. При этом конструкция машины усложняется и возникает необходимость настраивания системы к различным типам почв [5-6]. Третий способ снижения колебаний тяглового сопротивления связан с использованием при обработке почве более совершенных сельскохозяйственных машин с вращающимися системами, использование которых менее энергоемко. Кроме того, при планировании механизированных работ в течении одного рабочего дня необходимо учитывать минимизацию 
затрат на выполнение агротехнических мероприятий и оптимизацию внутрихозяйственной логистики (сокращение простоев). Это связано оперативным внесением изменений в технологические операции и расчеты экономических издержек, предусмотренных на производство сельскохозяйственных работ [7-8]. Мониторинг выполнения полевых механизированных работ реализуется посредством внедрения в производственный процесс интеллектуальной системы управления в интеграции с ГИС, программно-логическим контроллером ГЛОНАCC/GPS приемником и GSM-модемом, специализированными базами данных и программным обеспечением [9-10]. В отечественной ГИС «Панорама Агро» для работы с базой данных сельскохозяйственной техникой используется лицензионная система управления базой данных Microsoft SQL Server [11]. Это ограничивает возможности пользователя на внесение изменений в базы данных сельскохозяйственной техники и технологических операций. Современные СУБД реляционного типа поддерживают нетемпоральные модели и базы данных, в которых хранится единственное состояние объектов предметной области, т.е. текущее [12-13]. Для актуализации пространственно-временной информации разрабатываются агроэкологические информационные системы [14-16]. Такие системы предназначены для поддержки принятия решений в земледелии [9-10]. В тоже время имеются функциональные возможности ограничения для возможности построения динамических моделей. ГИС ArcGIS характеризуется расширенным набором процедур, направленных на обработку зависимостей в пространственно-временном аспекте и возможности использования экспертных знаний при принятии решений. Ограниченные функциональные возможности ГИС для анализа темпоральных параметров отражаются на достоверности решений [17-19].

Для оценки и эффективности снижения тяглового сопротивления машины, расчета эффективности выполнения механизированных работ необходим интегрированный подход разработки пространственной базы данных землепользования и базы данных характеристик сельскохозяйственных машин. 
Цель работы состоит в разработке темпоральной модели данных для выбора сельскохозяйственной техники с учетом технологических свойств земельных участков.

Научная новизна работы заключается в разработке методического подхода интегрирования пространственной базы данных землепользования и реляционной базы данных характеристик сельскохозяйственных машин.

\section{Методы исследований}

В работе использованы методы проектирования картографических баз данных и геоинформационных моделей географических информационных систем и методы проектирования баз данных.

Для разработки геоинформационной модели использована полнофункциональная ГИС ArcGIS. Для создания интеллектуальных информационных систем, направленных на поддержку принятий решений в реальном времени, требуется привлечение динамической составляющей в картографические и специализированные базы данных. В работе разработана темпоральная модель данных и соответствующие средства для управления данной моделью в форме темпоральной базы данных и процедур доступа к данным. Выполненный анализ функциональных возможностей современных систем управления базами данных показал, что большое распространение получают свободно распространяемые СУБД, обладающие возможностями облачного хранения данных. Доступной в использовании, легко внедряемой в различные программные решения является СУБД SQLite. В частности, SQLite направлена на хранение и быстрый доступ к данных [20-21].

\section{Результаты исследований}

Разработана темпоральная модель данных (ТМД) состоит из элементов и структур данных, отражающих изменения элементов во времени. Модель данных отличается наличием времени операции и времени фиксации факта с использованием временных меток, необходимых в дальнейшем для моделирования: 
- время фиксации события (начало выполнения технологической операции), отражающее время события;

- время операции - временная метка, фиксирующая продолжительность выполнения технологической операции по обработке почвы;

- время сбора данных - временная метка с указанием времени сбора внешних данных - картографических и иных данных.

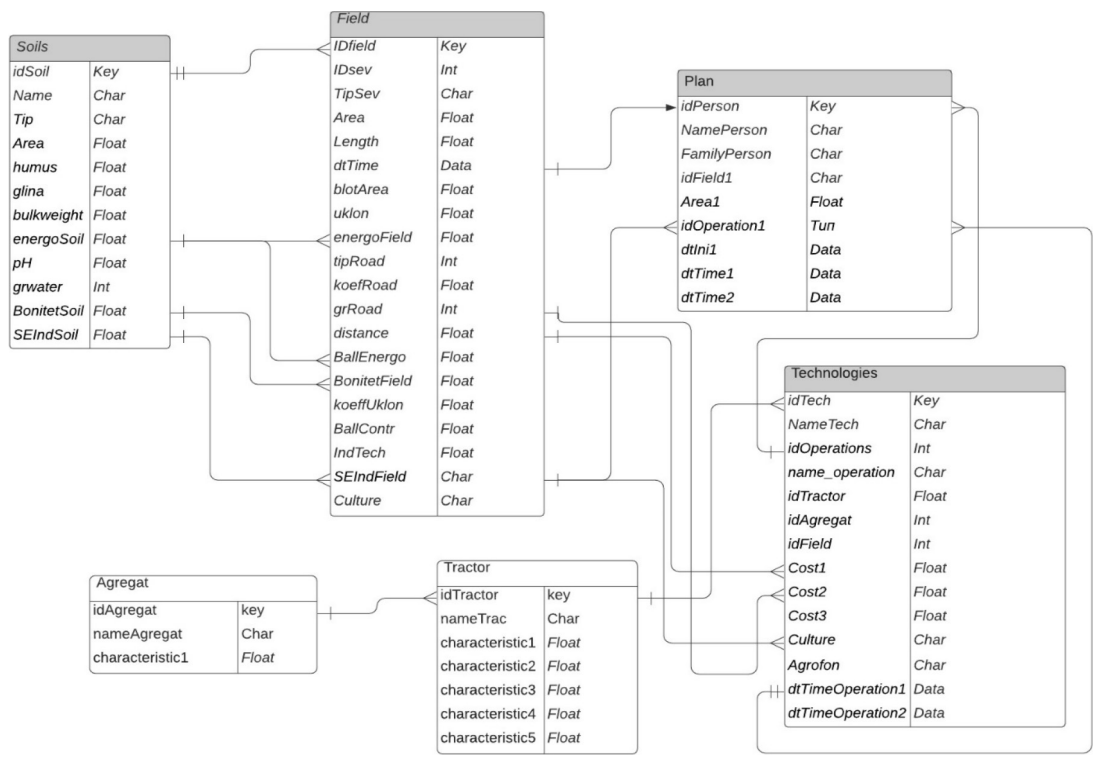

Рис. 1. Темпоральная модель данных

Согласно предложенной модели выделяются основные сущности земельные участки, почвы, тракторы, технологические карты, сельскохозяйственные агрегаты и сельскохозяйственные сотрудники. Перечисленные сущности представляют собой реляционные таблицы, включающие темпоральные данные, связанные между собой связями типа один-ко-многим или многие-ко-многим. Темпоральные атрибуты использованы в таблице участки для фиксирования временного параметра сельскохозяйственной культуры и величины урожайности. Темпоральные атрибуты присутствуют в таблице сельскохозяйствен- 
ные сотрудники для составления ежедневного плана, фиксирования в виде переменной времени начала выполнения работ, окончания работ, простоев. Темпоральные атрибуты времени необходимы в таблице технологические операции с целью фиксирования времени и сроков выполнения работ по обработке почвы. Для практической создана геоинформационная модель на примере землепользования ЗАО «Мирный» Коченевского района Новосибирской области, описываемая множеством картографических объектов и отношений между ними. В пространственной базе данных созданы пространственные классы объектов, характеризующие климатические, почвенные, геоморфологические особенности, а также использование земель. Сущность земельные участки описана набором геометрических и атрибутивных свойств, отражающих пространственные (площадь, периметр) и также технологические свойства земельных участков. К таким свойствам отнесены: длина гона участка, балл энергоемкости почв, удельное сопротивление почв, каменистость почв, угол наклона рельефа, коэффициент наклона рельефа, внутрихозяйственная удаленность, коэффициент группы дорог, коэффициент наклона рельефа по маршруту следования. Практическая реализация выполнена с использованием геоинформационной системы ArcGIS 10.6.

Разработана база данных тяглово-сцепных свойств тракторов. Тяглово-сцепные свойства тракторов (автомобилей) зависят от конструктивных особенностей машин, сцепного веса и др. трактор представляет собой сложный комплекс механизмов и систем, выполняющих определенные функции, связанные с двигателем, трансмиссией, ходовой системой, остовом, механизмами управления движением трактора, системой электрооборудования, рабочим и вспомогательным оборудованием, навесной гидравлической системой. При движении по полю машинно-тракторный агрегат испытывает динамическое воздействие, которое связано с различными условиями рельефа, неоднородности почв по механическому составу, энергоемкости почв, наличия камней, корней, агрофона [1]. В результате исследований была разработана база данных сельскохозяйственной техники, имеющяя сущности: земельные участки, сельскохозяйственные машины, 
агрегаты. С использованием СУБД SQLite были созданы таблицы, отражающие тяглово-сцепные свойства современных зарубежных и отечественных тракторов и агрегатов (рис. 2).

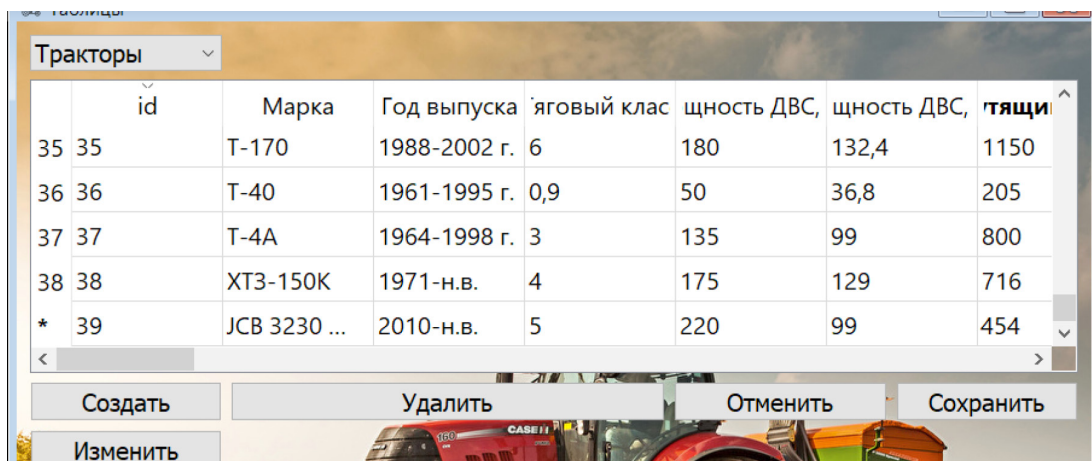

Рис. 2. База данных тракторы

Разработанная база данных позволяет осуществлять выбор сельскохозяйственной техники и может быть использована для сравнительного анализа подбора разных вариантов машинно-тракторных агрегатов с учетом технологических свойств земельных участков.

В ходе работы была разработана программа для оптимального выбора сельскохозяйственной техники с использованием языка Python (рис. 3).

\footnotetext{
耳5 Программа для подбора сельскохозяйственной техники

База Данных Расчеты Технологические карты Справка
}

дक्. Определение тягово-сцепных свойств трактора

Марка трактора Передача Величина уклона Тип почвы

Беларусь $82.1 \vee 5 \quad$ 0 $5003 \quad$ Целина, залежь

Рассчитать

1.1 Номинальное значение касательной силы тяги $=18.33 \mathrm{\kappa H}$

1.2 Сцепной вес трактора $=21.51 \mathrm{kH}$

1.3 Максимальная сила сцепления $=19.36 \mathrm{kH}$

1.4 Сцепление достаточное, движущая сила $=18.33 \mathrm{kH}$

1.5 Сила сопротивления на перекатывание трактора $=5.14 \mathrm{kH}$

1.6 Сила сопротивления на преодоление подъема трактором $=0.1 \mathrm{kH}$

1.7 Крюковое усилие трактора $=13.1 \mathrm{kH}$

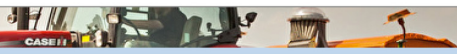

Рис. 3. Программа для оптимального подбора сельскохозяйственной техники 
При использовании программы выполняется расчет тягловосцепных свойств тракторов, а также экономических показателей с учетом технологических свойств земельного участка (угла наклона рельефа, энергоемкости почв, длины гона, предшественника).

Предложенная темпоральная модель данных может быть использована для составления ежедневного плана при выполнении механизированных работ, а также решения логистичеких задач. Данная темпоральная модель данных позволяет на уровне разрабатываемой программы использовать традиционные технологии реляционных СУБД и картографические базы данных. Дальнейшие исследования связаны с функциональным расширением базы данных и программы.

\section{Список литературы}

1. Щитов С.В. Повышение тягово-сцепных свойств мобильных энергетических средств в транспортно-технологическом обеспечении АПК Дальневосточного федерального округа: монография / С.В. Щитов, З.Ф. Кривуца, Н.Н. Сенникова, Н.Ф. Двойнова. Южно-Сахалинск: СахГУ, 2017. 176 с.

2. Снижение тяглового сопротивления сельскохозяйственных машин за счет минимизации его колебаний при обработке тяжелосуглинистых почв / А.Н. Цепляев, Р.А. Косульников, В.А. Цепляев, С.С. Полторынкин // Вестник ФГОУ ВПО «МГАУ им В.П. Горячкина». 2019. №2 (90). С.14-19.

3. Кузнецов Н.Г., Гапич Д.С., Назаров Е.А. Оптимизация жесткости упругого элемента в креплении рабочего органа культиватора BOURGAULT 8810 //Научное обозрениею Саратов. 2010. № 6. С. 89-93.

4. Гапич Д.С., Косульников Р.А., Чумаков С.А. Способы разрушения почвенного пласта с минимальными затратами энергии // Мировые научнотехнологические тенденции социально-экономического развития АПК и сельских территорий: матер. межунар. научно-практич. конф., посвященной 75-летию окончания Сталинградской битвы, 2018. С. 346-252.

5. Цепляев В.А., Матасов А.Н. Агрегат для удаления сорняков методом теребления // Сельский механизатор. 2014. № 9. С. 21-25.

6. Цепляев В.А., Матасов А.Н., Цепляев А.Н. Обоснование применения роторного агрегата для борьбы с сорняками методом теребления // 
Известия Нижневолжского агроуниверситетского комплекса: наука и высшее профессиональное образование. 2017. № 2. С. 256-263.

7. Каличкин В.К., Павлова А.И., Шоба В.Н., Каличкин А.В. Интеграция агроэкологических и технологических свойств земель // Достижения науки и техники АПК, 2019. Т. 33. № 3. С. 11-14.

8. Павлова А.И., Павлов А.В. Анализ методов коррекции цифровых моделей рельефа, построенных по спутниковым данным // Автометрия, 2018. Т.54. № 5. С. 25-32.

9. Павлова А.И., Фомина А.Е. Создание информационной системы для оценки контрастности почвенного покрова // В мире научных открытий, 2015. № 8.1 (68). С. 532-540.

10. Павлова А.И., Каличкин В.К. Использование геоморфометрического анализа рельефа при создании базы данных сельскохозяйственных земель // Сибирский вестник сельскохозяйственной науки, 2016. № 5 (252). C. 5-14.

11. Королев А.А. Технологии ГИС в управлении земледелием // Геоматика. 2011. № 2. С. 80-84.

12. Балдин А.В., Тоноян С.А., Елисеев Д.В. Анализ избыточности темпоральных баз данных средствами реляционных СУБД. URL: https:// cyberleninka.ru/article/n/analiz-izbytochnosti-hraneniya-temporalnyhdannyh-sredstvami-relyatsionnyh-subd (дата обращения 05.12.2020)

13. Тоноян С.А., Сараев Д.В. Темпоральные базы данных и их свойства. https://oracle-patches.com/images/000_pdf/1333.pdf (дата обращения 05.12.2020).

14. The role of agroecology and integrated farming systems in agricultural sustainability / Edwards C.A., Grove T.L., Harwood R.R., Pierce Colfer C.J. // Agriculture, Ecosystems and Environment.1993. Vol.46. Is. 1-4. P.99-121. https://doi.org/10.1016/0167-8809(93)90017-J.

15. Lacombre C., Couix N., Hazard L. Designed agroelological farming systems with farmers: a review // Agricultural systems. 2018, vol. 165, pp. 208-220. https://doi.org/10.1016/j.agsy.2018.06.014

16. Carolan M. Smart Farming Techniques as political ontology: access, sovereignty and performance of neoliberal and not-so-neoliberal worlds // Sociologia Ruralis, November 2017. DOI: 10.1111/soru.12202 (дата обращения 19.09.2020). 
17. Беляков С.Л., Белякова М.Л., Савельева М.Н. Образная модель представления опыта принятия решений с помощью геоинформационных систем // Геоинформатики. 2014. № 4. С. 23-28.

18. ГИС-технологии сравнения карт и управления развитием территории / Черемисина Е.Н., Спивак И.Л., Спивак Л.Ф., Соколов А.С. // Геоинформатика 2014. № 4. С.29-37.

19. Динамическая геоинформационная модель для задач управления материальными потоками / С.Л. Беляков, А.В. Боженюк, М.Л. Белякова, А.А. Глушков // Известия ЮФУ. Технические науки. №9 (182), сентябрь 2016. URL: http://old.izv-tn.tti.sfedu.ru/wp-content/ uploads/2016/9/7.pdf (дата обращения 05.12.2020).

20. Nemetz S., Schmitt S., Freiling F. A standardized corpus for SQLite database forensics // Digital Investigation, 2018, no.24, pp. 121-130. https://doi.org/10.1016/j.diin.2018.01.015

21. About SQLite. URL: https://www.sqlite.org/about.html (дата обращения 05.12.2020).

\section{References}

1. Shchitov S.V., Krivutsa Z.F., Sennikova N.N., Dvoynova N.F. Povyshenie tyagovo-stsepnykh svoystv mobil'nykh energeticheskikh sredstv $v$ transportno-tekhnologicheskom obespechenii APK Dal'nevostochnogo federal'nogo okruga [Improvement of the traction-coupling properties of mobile power facilities in the transport and technological support of the agro-industrial complex of the Far Eastern Federal District]. Yuzhno-Sakhalinsk: SakhGU, 2017. 176 p.

2. Tseplyaev A.N., Kosul'nikov R.A., Tseplyaev V.A., Poltorynkin S.S. Vestnik FGOU VPO «MGAU im V.P. Goryachkina». 2019. №2 (90). P.14-19.

3. Kuznetsov N.G., Gapich D.S., Nazarov E.A. Nauchnoe obozrenieyu Saratov. 2010. № 6. P. 89-93.

4. Gapich D.S., Kosul'nikov R.A., Chumakov S.A. Mirovye nauchno-tekhnologicheskie tendentsii sotsial'no-ekonomicheskogo razvitiya APK $i$ sel'skikh territoriy: mater. mezhunar. nauchno-praktich. konf., posvyashchennoy 75-letiyu okonchaniya Stalingradskoy bitvy [World scientific and technological trends in the socio-economic development of the agro-industrial complex and rural areas: mater. mezhunar. scientific and 
practical Conf., dedicated to the 75th anniversary of the end of the Battle of Stalingrad], 2018. P. 346-252.

5. Tseplyaev V.A., Matasov A.N. Sel'skiy mekhanizator. 2014. № 9. P. 21-25.

6. Tseplyaev V.A., Matasov A.N., Tseplyaev A.N. Izvestiya Nizhnevolzhskogo agrouniversitetskogo kompleksa: nauka i vysshee professional'noe obrazovanie. 2017. № 2. P. 256-263.

7. Kalichkin V.K., Pavlova A.I., Shoba V.N., Kalichkin A.V. Dostizheniya nauki i tekhniki APK, 2019. V. 33. № 3. P. 11-14.

8. Pavlova A.I., Pavlov A.V. Avtometriya, 2018. V.54. № 5. P. 25-32.

9. Pavlova A.I., Fomina A.E. V mire nauchnykh otkrytiy, 2015. № 8.1 (68). P. 532-540.

10.Pavlova A.I., Kalichkin V.K. Sibirskiy vestnik sel'skokhozyaystvennoy nauki, 2016. № 5 (252). P. 5-14.

11. Korolev A.A. Geomatika. 2011. № 2. P. 80-84.

12. Baldin A.V., Tonoyan S.A., Eliseev D.V. Analiz izbytochnosti temporal'nykh baz dannykh sredstvami relyatsionnykh SUBD [Analysis of the redundancy of temporal databases using relational DBMS]. URL: https://cyberleninka.ru/article/n/analiz-izbytochnosti-hraneniya-temporalnyh-dannyh-sredstvami-relyatsionnyh-subd (accessed 05.12.2020)

13. Tonoyan S.A., Saraev D.V. Temporal'nye bazy dannykh $i$ ikh svoyst$v a$. https://oracle-patches.com/images/000_pdf/1333.pdf (accessed 05.12.2020).

14.Edwards C.A., Grove T.L., Harwood R.R., Pierce Colfer C.J. The role of agroecology and integrated farming systems in agricultural sustainability. Agriculture, Ecosystems and Environment.1993. Vol.46. Is. 1-4. P.99-121. https://doi.org/10.1016/0167-8809(93)90017-J.

15.Lacombre C., Couix N., Hazard L. Designed agroelological farming systems with farmers: a review. Agricultural systems. 2018, vol. 165, pp. 208-220. https://doi.org/10.1016/j.agsy.2018.06.014

16. Carolan M. Smart Farming Techniques as political ontology: access, sovereignty and performance of neoliberal and not-so-neoliberal worlds. Sociologia Ruralis, November 2017. DOI: 10.1111/soru.12202 (accessed 19.09.2020).

17. Belyakov S.L., Belyakova M.L., Savel'eva M.N. Geoinformatiki. 2014. № 4. P. 23-28. 
18. Cheremisina E.N., Spivak I.L., Spivak L.F., Sokolov A.S. Geoinformatika 2014. № 4. P. 29-37.

19. Belyakov S.L., Bozhenyuk A.V., Belyakova M.L., Glushkov A.A. Dinamicheskaya geoinformatsionnaya model' dlya zadach upravleniya material'nymi potokami [Dynamic geoinformation model for the tasks of materials management]. Izvestiya YuFU. Tekhnicheskie nauki. №9 (182), 2016. URL: http://old.izv-tn.tti.sfedu.ru/wp-content/uploads/2016/9/7. pdf (accessed 05.12.2020).

20. Nemetz S., Schmitt S., Freiling F. A standardized corpus for SQLite database forensics. Digital Investigation, 2018, no.24, pp. 121-130. https:// doi.org/10.1016/j.diin.2018.01.015

21. About SQLite. URL: https://www.sqlite.org/about.html (accessed 05.12.2020).

\section{ДАННЫЕ ОБ АВТОРЕ}

Павлова Анна Илларионовна, кандидат технических наук, доцент Новосибирский государственньй университет экономики и управления; Сибирский федеральный научный ичентр агробиотехнологий СФНЦА РАН

ул. Каменская, 56, г. Новосибирск, 630099, Российская Федераџия; п. Краснообск, ул. Центральная, Новосибирская обл., 633501, Российская Федерация annstab@mail.ru

\section{DATA ABOUT THE AUTHOR}

Pavlova Anna Illarionovna Associate Professor, Candidate of Technical Sciences

Novosibirsk State University of Economics and Management; Siberian federal scientific center of agrobiotechnologies SFNZA RAHN 56, Kamenskaya Str., Novosibirsk, 630099, Russian Federation; Krasnoobsk, Novosibirsk region, 633501, Russian Federation annstab@mail.ru

ORCID: 0000-0001-6159-1439

ResearcherID: ABI-1009-2020

Scopus AuthorID: 57194525073 